\title{
ON COMPLETE MONOTONICITY OF SOME FUNCTIONS RELATED TO MEANS
}

\author{
ÁDÁM BESENYEI
}

Abstract. We show the complete monotonicity of some functions related to the Stolarsky mean which was a problem of S.-X. Chen and F. Qi (2007) [15]. In the proof, the connection between operator monotone and completely monotonic functions is used.

Mathematics subject classification (2010): 26A48, 26E60.

Keywords and phrases: completely monotonic function, operator monotone function, Bernstein function, Stolarsky mean.

\section{REFERENCES}

[1] H. Alzer And C. Berg, Some classes of completely monotonic functions, Annales Acad. Sci. Fenn. Math. 27, 2 (2002), 445-460.

[2] R. Bhatia, Matrix Analysis, Springer, New York, 1996.

[3] R. Bhatia, H. Kosaki, Mean matrices and infinite divisibility, Linear Algebra Appl. 424 (2007), $36-54$.

[4] R. P. BoAs, JR., Signs of derivatives and analytic behavior, Amer. Math. Monthly 78, 10 (1971), $1085-1093$.

[5] P. S. Bullen, Handbook of means and their inequalities, Mathematics and its Applications, Vol. 560, Kluwer Academic Publishers Group, Dordrecht, 2003.

[6] T. BuRić, N. Elezović, Some completely monotonic functions related to the psi function, Math. Inequal. Appl. 14, 3 (2011), 679-691.

[7] C.-P. CHEN, Complete monotonicity and logarithmically complete monotonicity properties for the gamma and psi functions, J. Math. Anal. Appl. 336, 2 (2007), 812-822.

[8] T. FURUTA, Concrete examples of operator monotone functions obtained by an elementary method without appealing to Löwner integral representation, Linear Algebra Appl. 429, 5-6 (2008), 972-980.

[9] H. VAN HAERINGEN, Completely monotonic and related functions, J. Math. Anal. Appl. 204 (1996), 389-408.

[10] F. HANSEN, Some operator monotone functions, Linear Algebra Appl. 430 (2009), 795-799.

[11] E. HeinZ, Beiträge zur Störungstheorie der Spektralzerlegung, Math. Ann. 123 (1951), 415-438.

[12] F. Kubo, T. Ando, Means of positive linear operators, Math. Ann. 246 (1980), 205-224.

[13] E. B. Leach, M. C. Scholander, Extended mean values, Amer. Math. Monthly 85 (1978) 84-90.

[14] K. LöwnER, Über monotone Matrixfunktionen, Math Z. 38 (1934), 177-216.

[15] F. QI, S.-X. Chen, Complete monotonicity of the logarithmic mean, Math. Inequal. Appl. 10, 4 (2007), 799-804.

[16] F. QI, S. GuO, B.-N. GuO, Complete monotonicity of some functions involving polygamma functions, J. Comput. Appl. Math. 233, 9 (2010), 2149-2160.

[17] R. L. Schilling, R. Song, Z. VondraČEK, Bernstein Functions: Theory and Applications, de Gruyter Studies in Mathematics 37, Springer, Berlin, 2010.

[18] H. ŞeVli, N. BAtiR, Complete monotonicity results for some functions involving the gamma and polygamma functions, Math. Comput. Model. 53 (2011), 1771-1775.

[19] K. B. Stolars Ky, Generalizations of the logarithmic mean, Math. Mag. 48 (1975), 87-92.

[20] D. V. WiddeR, The Laplace Transform, Princeton University Press, Princeton, 1946. 